\title{
Scarlet Fever Associated with Hepatitis - A Report of Two Cases
}

\author{
M. Girisch, U. Heininger
}

\begin{abstract}
Summary
Infection with group A beta-hemolytic streptococci (GABHS) is the most common bacterial cause of acute pharyngitis and tonsillitis beyond infancy. We report on two patients with scarlet fever associated with hepatitis. The patients (boys aged 6 and 7 years) both presented with a scarlatiniform rash, dark urine and light-colored stools. Laboratory studies revealed elevated liver transaminases and negative antibody tests against hepatitis viruses $A, B$ and $C$, cytomegalovirus and Epstein-Barr virus. Both patients were treated with antibiotics and recovered completely within a few days. Although the association between scarlet fever and hepatitis has been known for many decades, the pathogenesis is still unknown. Physicians treating patients with group A beta-hemolytic streptococcal infections should be aware of possible hepatic involvement.
\end{abstract}

\section{Key Words}

Hepatitis · GABHS · Streptococcus · Scarlet fever

Infection 2000; 28: 251-253

\section{Introduction}

Infection with group A beta-hemolytic streptococci (GABHS) is the most common bacterial cause of acute pharyngitis and tonsillitis beyond infancy. Furthermore, erythrogenic toxin-producing GABHS strains can cause scarlet fever, which is characterized by a fine red rash, a swollen red tongue (strawberry tongue) and desquamation of the skin on the trunk, face and fingertips during convalescence. In addition, a variety of other manifestations caused by GABHS infection - including otitis media, sinusitis, mastoiditis, pneumonia, empyema, omphalitis, osteomyelitis, streptococcal toxic shock syndrome and meningitis - have been reported [1]. Although hepatitis has previously been described in association with scarlet fever and other GABHS infections in children and adults, most of these reports are not recent and are not mentioned in standard pediatric or pediatric infectious disease textbooks [2-8]. We would therefore like to report on two patients who recently presented with this manifestation.

\section{Case Reports \\ Case 1}

A 6-year-old boy who had suffered typical scarlet fever for 5 days was admitted to our hospital because of abdominal pain and sonographically diagnosed enlargement of the gall bladder. On examination, he presented with a typical scarlatiniform rash (most prominent in the genital region), sore red throat and enlarged cervical lymph nodes without other abnormal findings. The boy was afebrile. Remarkably, the urine was dark and the stools were lightcolored but there was no jaundice. Laboratory tests on admission revealed elevated transaminases in serum (GOT $30 \mathrm{U} / \mathrm{l}$, GPT $110 \mathrm{U} / 1$, GGT $78 \mathrm{U} / 1$, normal values: all $<20 \mathrm{U} / 1)$, and a mildly elevated bilirubin of $1.8 \mathrm{mg} / \mathrm{dl}$. Alkaline phosphatase (511 U/l) and LDH (285 U/l) were in the upper normal range (110-600 U/l and $<280 \mathrm{U} / 1$, respectively). A full blood count was also within the normal range; C-reactive protein (CRP) in serum was $<0.3 \mathrm{mg} / \mathrm{dl}$. Serum assays for $\mathrm{IgM}$ and $\mathrm{IgG}$ antibodies against hepatitis viruses $\mathrm{A}, \mathrm{B}$ and $\mathrm{C}$, cytomegalovirus and Epstein-Barr virus were all negative. The antistreptolysin test (ASL) was elevated at $600 \mathrm{IU} / \mathrm{ml}$. Since the patient had already been on erythromycin for 5 days, a throat swab for culture was not performed. However, a GABHS antigen test was positive. Since symptoms of scarlet fever had already improved, antibiotic therapy was left unchanged and continued for a further 9 days. The patient recovered completely within 6 days and was discharged. On discharge, ultrasound examinations of the liver and gallbladder were unremarkable, GOT was $26 \mathrm{U} / \mathrm{l}$, GPT $58 \mathrm{U} / \mathrm{l}$, GGT $45 \mathrm{U} / \mathrm{l}$ and bilirubin was $0.8 \mathrm{mg} / \mathrm{dl}$. Desquamation of the skin had appeared in the genital region. Five months later ASL was $100 \mathrm{IU} / \mathrm{ml}$.

\section{Case 2}

A 7-year-old boy was acutely ill with scarlet fever when he presented at the hospital. He had a previous history of surgery for coarctation of the aorta and implantation of a ventriculo-peri-

\footnotetext{
M. Girisch

Pediatric Clinic, Friedrich-Alexander Universitity of Erlangen-Nürnberg, Loschgestr. 15, D-91054 Erlangen, Germany

U. Heininger (corresponding author)

University Children's Hospital (UKBB), PO Box; CH-4005 Basel,

Switzerland; Phone: +41-61-685 6565, Fax: 41-61-685 6012,

e-mail: Ulrich.Heininger@unibas.ch
}

Received: May 22, 2000· Accepted: June 14, 2000 
toneal shunt following hypoxic brain damage and development of a hydrocephalus. There was no obvious epidemiological link to patient 1 who had been in our hospital 3 months previously. The boy had been on penicillin for 4 days, he was still febrile $\left(40{ }^{\circ} \mathrm{C}\right)$ and his general condition was poor. As in patient 1 , there was pharyngitis, a scarlatiniform rash, dark urine and light-colored loose stools. On admission, CRP was $23 \mathrm{mg} / \mathrm{dl}$ and the white blood count was $9,200 / \mu \mathrm{l}$ with $81 \%$ neutrophils. Platelets were $198,000 / \mu 1$. Serum liver enzymes were elevated (GOT 91 U/1, GPT 133 U/1, GGT $238 \mathrm{U} / \mathrm{l}$ ) and bilirubin in serum was $2.7 \mathrm{mg} / \mathrm{dl}$ with $0.6 \mathrm{mg} / \mathrm{dl}$ of conjugated bilirubin. Alkaline phosphatase (493 U/1) and LDH (186 U/l) were within normal ranges. Serum assays for IgM and IgG antibodies against hepatitis viruses A, B and C, cytomegalovirus and Epstein-Barr virus were all negative except for presence of $\mathrm{IgG}$ antibodies against CMV. Analysis of CSF including culture was normal. A throat culture revealed growth of GABHS. For an initially suspected sepsis he was put on iv cefotaxim and vancomycin. The boy recovered quickly and was discharged after 10 days. On discharge, ASL was elevated at $400 \mathrm{IU} / \mathrm{ml}$, GOT, GPT and bilirubin serum values had decreased (23 U/1, $41 \mathrm{U} / 1$ and $0.9 \mathrm{mg} / \mathrm{dl}$, respectively) and were within the normal range 4 weeks later. GGT and alakaline phosphatase had reached their maxima on day 7 of hospital treatment ( $891 \mathrm{U} / 1$ and 1,577 U/1, respectively) and were also within the normal range upon control 4 weeks later.

\section{Discussion}

We saw two patients with a clinical diagnosis of scarlet fever and supportive laboratory evidence of GABHS infection who both experienced liver involvement during the course of their illness. Patient 1 had been on erythromycin for 5 days when symptoms of hepatitis started. Since erythromycin, like other macrolide antibiotics, is known to cause hepatic disturbances, one could argue that the patient's symptoms might have been drug-related. However, hepatitis caused by erythromycin is ususally more pronounced and does not resolve before the drug is discontinued $[9,10]$. In our patient hepatitis had already regressed several days before erythromycin therapy was stopped.

Hepatitis during scarlet fever was first reviewed by MacMahon and Mallory in 1931 [5]. Since then, only a few reports on this association in children and adults have been published. Kocak et al. [4] observed two Turkish girls with symptoms of hepatitis including jaundice which started a few days after onset of scarlet fever and which was of remarkably short duration ( 7 and 12 days, respectively). A needle biopsy of the liver in one of the girls revealed polymorphonuclear granulocytes infiltrating the portal area and degenerative changes in the hepatocytes. Similarly, a 29year-old woman and three young adults (aged 18 to 36 years) developed hepatitis within a few days of the onset of scarlet fever [2,3]. Furthermore, two adults (aged 22 and 62 years) were reported with severe kidney and liver involvement during streptococcal scarlet fever [6]. Liver biopsies from these two patients revealed edema of the portal spaces with infiltrates of lymphocytes, plasmocytes and polymorphonuclears and necrosis of hepatocytes. In a 68year-old woman who developed post-streptococcal reactive arthritis and transient hepatitis, liver biopsy revealed severe inflammation and piecemeal necrosis [7]. In this report, 4/24 $(17 \%)$ patients with post-streptococcal reactive arthritis developed mild, transient hepatitis. In addition, mild and evanescent abnormalities in liver function tests were seen in 25/39 patients with acute rheumatic fever and antecedent streptococcal infection [8]. The mild clinical course in our two patients did not justify liver biopsy.

In contrast to these reports, which clearly attribute hepatitis as a complication to scarlet fever and other streptococcal infections, one group suggested the opposite, namely that scarlatiniform eruption may be associated with viral hepatitis [11]. However, the findings in their case report (scarlatiniform skin eruption 6 days before darkening of urine, mild elevation of liver transaminases and no proven viral etiology of hepatitis) are more indicative of hepatic involvement in scarlet fever.

Hepatitis has also been found in patients with invasive GABHS infections. In a series reported from Canada, 15/24 $(63 \%)$ patients (comprising children and adults) with severe invasive GABHS infection had elevated liver transaminases indicative of hepatic involvement [12]. However, no further details on these patients were given. Furthermore, hepatitis was found as a major complication in children with meningitis caused by GABHS infection [13].

Taken together, all cases of hepatitis in association with GABHS reported so far occurred in close temporal relationship with scarlet fever (frequently several days after onset of the skin rash) with other streptococcal infections (acute rheumatic fever, post-streptococcal arthritis) or with invasive infections. Many of these patients demonstrated jaundice, while some were subicteric and therefore hepatitis may frequently be overlooked in patients with scarlet fever. The pathogenesis of liver involvement under these circumstances is unclear. Theoretically, direct toxic tissue injury as well as immunological mechanisms may play a role. Among an autopsy series of 59 cases of scarlet fever, jaundice was found in four [14]. Post-mortem cultures of blood and lungs yielded beta-hemolytic streptococci while those of liver tissue did not, thus there is lack of evidence of direct bacterial liver tissue damage. One could still argue for a hepatotoxic effect caused by streptococcal pyrogenic exotoxins which have been shown to induce cell damage via direct influence on lymphokines, e.g. tumor necrosis factor [15].

The frequency of hepatitis in children with scarlet fever is unknown but appears to be rare. Physicians treating patients with scarlet fever and invasive GABHS infections should be aware of the association.

\section{References}

1. Kaplan EL, Gerber MA: Group A, group C, and group G beta-hemolytic streptococcal infections. In: Feigin RD, Cherry JD (eds): Textbook of pediatric infectious diseases. W.B. Saunders, Philadelphia 1998, pp 1076-1088.

2. Beaudoin $M$, Saint-Louis $G$, Delorme J: Hépatite et fièvre scarlatine chez une jeune adulte. Tome 1982; 11:367-369. 
3. Fishbein WN: Jaundice as an early manifestation of scarlet fever. Report of three cases in adults and review of the literature. Ann Intern Med 1962; 57: 60-72.

4. Kocak N, Ozsoylu S, Ertugrul M, Ozdol G: Liver damage in scarlet fever: description of two affected children. Clin Pediatr 1976; 15: 462-464.

5. MacMahon HE, Mallory FB: Streptococcus hepatitis. Am J Pathol 1931; 7: 299-325.

6. Robbens E, De Man M, Schurgers M, Boelaert J, Lameire N: Systemic complications of streptococcal scarlet fever: two case reports and a review of the literature. Acta Clinica Belgica 1986; 41: 311-318.

7. Barnert AL, Terry EE, Persellin RH: Acute rheumatic fever in adults. JAMA 1975; 232: 925-928.

8. Jansen TL, Janssen M, de Jong AJ, Jeurissen ME: Post-streptococcal reactive arthritis: a clinical and serological description, revealing its distinction from acute rheumatic fever. J Intern Med 1999; 245: 261-267.

9. Hautekeete ML: Hepatotoxicity of antibiotics. Acta Gastroenterol Belg 1995; 58: 290-296.
10. Zafrani ES, Ishak KG, Rudzki C: Cholestatic and hepatocellular injury associated with erythromycin esters: report of nine cases. Dig Dis Sci 1979; 24: 385-396.

11. Prestia $A E$, Lynfield $Y L$ : Scarlatiniform eruption in viral hepatitis. Arch Derm 1970; 101: 352-355.

12. Demers B, Simor AE, Vellend $H$, Schlievert PM, Byrne S, Jamieson F, Walmsley S, Low DE: Severe invasive group A streptococcal infections in Ontario, Canada: 1987-1991. Clin Infect Dis 1993; 16: 792-800.

13. Murphy DJ: Group A streptococcal meningitis. Pediatrics 1983; 71: 1-5.

14. Brody H, Smith LW: The visceral pathology in scarlet fever and the related Streptococcus infections. Amer J Path 1936; 12: 373-399.

15. Stevens DL: Streptococcal toxic-shock syndrome: spectrum of disease, pathogenesis, and new concepts in treatment. Emerg Infect Dis 1995; 1: 69-78. 